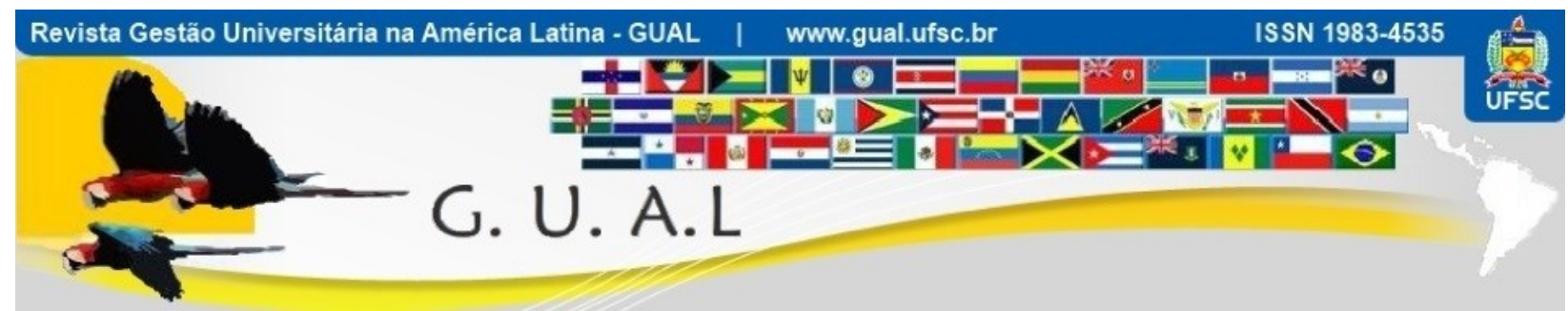

DOI: http://dx.doi.org/10.5007/1983-4535.2020v13n3p1

\title{
A GESTÃO DO CONHECIMENTO NA UNIVERSIDADE FEDERAL DE MATO GROSSO: UM ESTUDO DE CASO
}

\author{
KNOWLEDGE MANAGEMENT IN THE FEDERAL UNIVERSITY OF MATO \\ GROSSO: A CASE STUDY
}

\author{
Josiane de Oliveira Lobato, Doutora \\ https://orcid.org/0000-0002-4774-183X \\ josiane_deoliveira@hotmail.com \\ Universidade Nove de Julho | Programa de Pós-Graduação em Administração \\ São Paulo | São Paulo | Brasil \\ Elida Furtado da Silva Andrade, Doutora \\ https://orcid.org/0000-0001-7064-7633 \\ elidandrade@gmail.com \\ Universidade Nove de Julho | Programa de Pós-Graduação em Administração \\ São Paulo | São Paulo | Brasil \\ Emerson Antonio Maccari, Doutor \\ http://orcid.org/0000-0001-7085-224X \\ emersonmaccari@gmail.com \\ Universidade Nove de Julho | Programa de Pós-Graduação em Administração \\ São Paulo | São Paulo | Brasil
}

Recebido em 19/março/2019

Aprovado em 04/abril/2020

Publicado em 01/setembro/2020

Sistema de Avaliação: Double Blind Review 


\title{
RESUMO
}

Diante de um ambiente cada vez mais competitivo, globalizado e tecnológico, o surgimento da Internet e das tecnologias da informação fez com que a quantidade de dados disponíveis com suporte digital fosse ampliada e como consequência, o aumento da circulação das informações. As Instituições de Ensino Superior geram inúmeras informações, sejam para órgãos de controle, sejam para o Ministério da Educação, são informações armazenadas em seus bancos de dados, que se fossem coletadas, processadas e disseminadas, poderiam ser utilizadas para dar suporte ao planejamento estratégico, contribuindo assim, na tomada de decisão dos gestores. Neste sentido, é importante discutir a gestão da informação e do conhecimento nas organizações universitárias para que estas busquem a eficiência e eficácia. O objetivo deste trabalho é identificar as práticas de Gestão de Informação e do Conhecimento utilizadas pela gestão da Universidade Federal de Mato Grosso, através de um estudo de caso, realizado por meio de análise documental e de entrevistas com os Pró-reitores e Secretários. Como resultado, verificou-se que existem na instituição, iniciativas isoladas de gestão da informação, assim como não há uma estratégia explícita de gestão do conhecimento, sendo esta incipiente, uma vez que não se encontra disseminada na Instituição e por esta razão, é desconhecida da maioria dos servidores.

Palavras-chave: Gestão do Conhecimento. Gestão da Informação. Inteligência Competitiva.

\begin{abstract}
Before an increasingly competitive, globalized and technological environment, the emergence of the Internet and technology information has made the amount of data available with digital support broad and, as consequence, increased circulation of information. Higher Education Institutions generate a great deal of information, whether to the control agencies or to the Education Ministry, keeping it stored in their databases, which if collected, processed and disseminated could be used to support strategic planning, thus contributing to the decisionmaking of managers. In this sense, it is important to discuss the management of information and knowledge in university organizations so that they seek efficiency and effectiveness. The objective of this work is to identify the Information and Knowledge Management practices used in Federal University of Mato Grosso, through a case study, conducted through documentary analysis and interviews with the Pro-rectors and Secretaries. As a result, we verified that there are isolated initiatives of information management, just as well there is no explicit knowledge management strategy, being it incipient, once is not disseminated in the Institution and for this reason it is unknown of the majority of the servers.
\end{abstract}

Keywords: Knowledge Management. Information Management. Competitive Intelligence. 


\section{INTRODUÇÃO}

Com o surgimento e a popularização da informática entre os anos de 1960 e 1980, e posteriormente o surgimento da Internet e das tecnologias da informação, a partir dos anos de 1990, a quantidade de dados disponíveis em suporte digital foi ampliada e seu acesso tornouse mais fácil (FIALHO, 2010; DAVIS; STEPHENSON, 2006; MENEZES, 2005).

Entretanto, nas organizações de ensino superior no Brasil, em geral, as mudanças e inovações, principalmente gerenciais, acontecem de forma lenta, sobretudo nas IES públicas onde o orçamento é atrelado aos recursos públicos e em muitos casos, a administração universitária é caracterizada pela centralização, pela burocracia e pelo corporativismo (PEREIRA et al., 2011).

O ensino superior brasileiro encontra-se em expansão, de acordo com os últimos dados disponibilizados pelo Censo da Educação Superior, em 2017, havia 8.286.663 alunos matriculados, deste, $24,68 \%$ eram em instituições públicas, foram ofertados 35.380 cursos em 2.448 instituições de ensino superior (BRASIL, 2019), e esta expansão vem trazendo uma série de modificações e exigências para a gestão universitária.

Pereira et al. (2011) afirmam que um dos maiores desafios das organizações atualmente, e em particular das instituições de ensino superior, está em aprender a converter o conhecimento dos seus colaboradores em conhecimento organizacional. Para descobrir, gerenciar, desenvolver o capital intelectual e oferecer uma estrutura sobre a qual as Instituições de Ensino Superior/IES possam desenvolver estratégias úteis e valiosas para cumprir sua missão tornam-se necessárias a perfeita compreensão dos processos envolvidos e a instalação de um ambiente que propicie o trabalho do profissional do conhecimento (seja ele aluno, professor, pesquisador ou funcionário).

Ainda nesta perspectiva, as instituições geram inúmeras informações, sejam para cumprimento legal das exigências dos órgãos de controle, sejam para os indicadores de qualidade do Ministério da Educação. São informações armazenadas em seus bancos de dados, que poderiam ser utilizadas de forma a dar suporte ao planejamento estratégico, ou conforme explicam Gomes e Braga (2001), aos tomadores de decisões nas organizações, que trabalham com grande quantidade de dados em estado bruto e quantidade reduzida de informação com valor agregado e, como consequência, pouca inteligência para subsidiar o processo decisório. Tarapanoff (2001) defende que a gestão da informação e do conhecimento, bem como a inteligência competitiva, constituem, do ponto de vista teórico, 
uma nova metodologia, uma nova abordagem e síntese teórica, para o planejamento e administração estratégica das organizações e para a sua tomada de decisão.

Neste sentido, é importante que se introduza a discussão a respeito da gestão do conhecimento nas organizações universitárias, de modo que estas busquem a eficiência e eficácia. Diante do exposto, este trabalho tem o objetivo de identificar as práticas de Gestão do Conhecimento utilizadas na Universidade Federal de Mato Grosso, através de um estudo de caso, realizado por meio de entrevistas com roteiro semiestruturado e análise documental.

Como resultado, espera-se verificar o estágio em que se encontra a aplicação da gestão do conhecimento na Universidade Federal de Mato Grosso em busca da inteligência competitiva.

Este estudo é apresentado em cinco seções, incluindo esta introdução. A segunda seção apresenta o referencial teórico ao qual o tema está embasado. Em seguida, o método de pesquisa é descrito, e na quarta seção, os resultados e discussão são apresentados. Por fim, são feitas as considerações finais do estudo, bem como as limitações do trabalho e sugestões de pesquisas futuras.

\section{REFERENCIAL TEÓRICO}

\subsection{INTELIGÊNCIA COMPETITIVA}

A capacidade de perceber as mudanças em seus ambientes interno e externo, em nível nacional e internacional, induziram a adoção da inteligência econômica nas organizações, com o intuito de antecipar estas mudanças, podendo se preparar melhor para este enfrentamento. As empresas anglo-saxônicas, britânicas e americanas foram as primeiras a adotarem a inteligência de negócios (TARAPANOFF, 2006).

No processo de inteligência entende-se que os gestores devam possuir informações relevantes para o negócio, de maneira formal e sistemática, guiado no processo de tomada de decisão. Assim, deve haver um consenso entre os tomadores de decisão no que se refere a dados, informação, inteligência e conhecimento, de forma que possam interpretá-los de forma correta, separando-os entre fatos, missão, visão organizacional, mercado entre outros (MILLER, 2002).

São encontradas na literatura teorias sobre o processo de inteligência propostas por diversos autores sob diferentes formas, e em sua maioria, referem-se à inteligência como elemento essencial para o planejamento estratégico (DISHMAN; CALOF, 2008). Um dos 
conceitos diz respeito à inteligência econômica, que tem por objetivo fornecer aos gestores os conhecimentos necessários para uma ampla análise do ambiente organizacional, considerando-os em suas tomadas de decisão, circundada por conceitos de inovação, informação e conhecimento. Conceitua-se inteligência econômica como um conjunto de buscas coordenadas, além do tratamento, da distribuição e da proteção da informação relevante, obtida dentro da legislação. $\mathrm{Na}$ visão organizacional, a inteligência econômica transformou-se em inteligência de negócios e, por fim, em inteligência competitiva (TARAPANOFF, 2006).

A inteligência competitiva sempre esteve presente nas empresas, de forma intuitiva, em particular nas pequenas empresas. No entanto, na "Era do Conhecimento", as empresas necessitam exercitar a prática da inteligência competitiva, realizando um estudo detalhado da realidade organizacional onde está inserida a empresa, para se desenvolver e, até mesmo, se manter (FULD, 2007).

A inteligência competitiva pode ser compreendida como:

Um processo sistemático que transforma pedaços esparsos de dados em conhecimento estratégico. É informação sobre produtos específicos e tecnologia, é monitoramento de informações externas que afetam o mercado da organização, como a informação econômica, regulatória, política e demográfica. (TARAPANOFF, 2001, p. 344).

Segundo Starec et al. (2012) esta é uma prática de tratamento de informações relevantes de uma organização visando sua competitividade inteligente no mercado. Neste sentido, Tarapanoff (2006), complementa ao afirmar que a inteligência competitiva foi definida como um processo de aprendizado incentivado pela competição, alicerçado sobre a informação, permitindo a otimização da estratégia corporativa. Para sua execução é necessário a utilização sistemática de dados e informações que, passando por um processo de análise e agregação de valor, faz uso de todo seu conhecimento, individual e coletivo.

Ampliando o conceito de Inteligência Competitiva, Rodrigues e Riccardi (2007) a define como um sistema corporativo que permite uma tomada de decisão segura, considerando sua ambiência, interna e externa, e sua capacidade financeira, dando consistência e racionalidade aos objetivos organizacionais. Desse modo, segundo os mesmos autores, a inteligência competitiva permite à empresa antecipar-se a possíveis mudanças de mercado, assegurando maior eficiência das estratégias da empresa. 
Kahaner (1997) defende que a função mais relevante da inteligência competitiva está representada em seu poder de decisão, pois, seu objetivo é proporcionar aos gestores conhecimentos antecipados que os levem a suprir as necessidades do seu consumidor, envolvendo a identificação de dados e informações relevantes ao decisor.

Para Herring (2005), há duas maneiras de identificar as necessidades de inteligência para a empresa. A primeira delas é a "responsiva", a qual exige que a área de inteligência competitiva esteja preparada para responder a demanda originada pelos gestores, estando pronta para responder e prever as necessidades dos clientes. A segunda maneira é chamada de "proativa", nesse modo, a área de inteligência competitiva tem a iniciativa de entrevistar os tomadores de decisão da empresa, com o intuito de auxiliá-los a identificar e definir as demandas por informações.

Rodrigues e Riccardi (2007), desenvolveram um processo de Inteligência Competitiva, adaptado de estudos de Correia (2006), usando a lógica do processo clássico de Inteligência Competitiva, proposto originalmente por Herring (1999).

Este modelo, segundo Rodrigues, Sierra e Rechziegel (2014), aparenta ser mais preciso e representativo que os apresentados anteriormente, o sistema, chamado pelos autores de MOSIPIC (Modelo Sistêmico do Processo de Inteligência Competitiva), é dividido em três fases, sendo uma de construção, uma de síntese e outra de operação. Na primeira fase, ocorre a identificação dos indicadores que envolvem o mercado concorrente da organização, criando as condições necessárias para competir. $\mathrm{Na}$ fase de síntese, define-se as políticas e orientações institucionais que norteiam as mudanças a serem alcançadas, no tempo e direção propostos. $\mathrm{Na}$ última fase do sistema, segundo os autores, é onde surgirá a oportunidade de se criar condições competitivas, preocupando-se em avaliar o desempenho das atividades de inteligência competitiva e sua real eficácia no processo de mudança na organização.

Para Rodrigues e Toledo (2011), a inteligência competitiva contribui com a estratégia da empresa, principalmente, com o processamento adequado da informação, levando a capacitação de pessoas e sistemas. Esta é uma função do sistema de inteligência competitiva, que para funcionar necessita de uma infraestrutura de Tecnologia da Informação (TI) disponível. Assim, cabe aos gestores de TI a função de identificar qual solução, ferramenta e/ou processo serão necessários para resolver as necessidades de informações dos gestores do sistema de inteligência competitiva, estes sim, responsáveis por coletar, analisar, processar e distribuir as informações requeridas pelos gestores da empresa. 
Desse modo, a TI deve ser vista como um elemento coadjuvante no sistema de inteligência competitiva, tendo como função impulsionar e facilitar a busca pela informação na organização. Assim, defende-se que o sistema de inteligência competitiva deve estar orientado para pessoas, com necessidades e culturas específicas (DAVENPORT; PRUSAK, 1998). Pois, não basta possuir uma notável estrutura de inteligência, antes, torna-se necessário incluir redes humanas, com rigorosa capacidade analítica, para transformar dados em inteligência estratégica, relevante, disponível e que, principalmente, assegurem que seus resultados cheguem aos tomadores de decisão, para que o movimento estratégico da empresa, definido pela inteligência competitiva, seja caracterizado como vantagem competitiva (DAY, 1999). Seguindo este pensamento, os tópicos a seguir, corroborarão com o entendimento deste autor ao trazer à discussão, a gestão da informação e do conhecimento.

\subsection{GESTÃO DA INFORMAÇÃO}

Ao observar as organizações como uma rede de atividades inter-relacionadas, nota-se que estas não conseguem acompanhar o ritmo das mudanças que ocorrem na sociedade e, até mesmo, a necessidade de transformar o negócio. Sem esta compreensão, as organizações sentem a perda de controle da situação em decorrência do impacto das constantes mudanças, o que exige cada vez mais o estudo nessa direção. Assim, é imperativo a organização adotar modelos inovadores, buscando novos conhecimentos, reestruturando o seu conceito de gestão organizacional. Para tanto, a organização deverá conhecer amplamente seu ambiente interno e externo, assim como o meio que se relaciona, sendo proativa, estabelecendo metas e estratégias competitivas que deverão ser priorizadas na tomada de decisão (VALENTIM et al., 2003).

Desse modo, as empresas devem apresentar qualidade, agregar valor, inovar, serem flexíveis, ágeis e velozes, de modo cada vez mais efetivo e, para tanto, devem utilizar a habilidade de transformar dados corriqueiros em informações relevantes para uso, de forma a agregar valor ao negócio. Neste contexto, as empresas se diferenciam pelo seu capital intelectual e pela forma que utilizam as informações que dispõem (SIQUEIRA, 2005).

Para as organizações, associar a informação e as tecnologias ao seu uso tornou-se um recurso tão imprescindível quanto os recursos financeiros ou humanos (DAVENPORT; PRUSAK, 1998). Desse modo, a informação tornou-se um pré-requisito fundamental para o aperfeiçoamento de processos, produtos e serviços, revelando seu valor estratégico para a 
organização. Esta visão da informação surgiu com a evolução da gestão da informação, que mudou seu foco inicial de gestão de documentos e dados para gestão de recursos informacionais, levando à eficiência operacional. A partir desta concepção, mais estratégica, a gestão da informação passou a constar na estrutura formal da empresa e ser responsabilidade do alto escalão organizacional (TARAPANOFF, 2006).

Além da responsabilidade de gerir as informações, também são competências dos executivos estabelecerem políticas de informação aplicáveis na empresa; criar e manter estoques de informação; fazer a coordenação dessas informações; promover esforços para melhorar a qualidade da informação; criar espaços apropriados para produção/disseminação da informação baseados nas necessidades identificadas; planejar e partilhar informações em toda organização (DAVENPORT, 1994).

A literatura que versa sobre teoria organizacional afirma que a informação é criada e utilizada pelas organizações em três campos estratégicos. No primeiro, a empresa interpreta e dá significado às informações obtidas sobre o ambiente que a envolve e como ela está agindo, isso se chama gestão da informação e inteligência competitiva. No segundo campo, a organização, para inovar e aprender, ou seja, para realizar a gestão do conhecimento, combina as experiências de seus membros criando novos conhecimentos. No último campo, a informação é processada e analisada, para que possa ser utilizada na tomada de decisão de maneira estratégica, ou seja, executar a inteligência estratégica (CHOO, 2003).

O principal objetivo de uma gestão estratégica é obter vantagem competitiva e quanto mais relevância tiver a informação para o negócio da organização, maior e mais efetiva deverá ser a gestão sobre ela (SIQUEIRA, 2005). Com esta compreensão, passa-se a discutir a forma e a ação da estratégia da informação a ser executada, ou seja, descobrir como a informação poderá gerar vantagem competitiva e como implementar as ações que irão permitir que a estratégia se revele em resultados. Para essa compreensão são exigidos a utilização de sistemas e técnicas de coleta, seleção e interpretação de informações que apoiarão o processo de tomada de decisão da organização, os quais podem ser formais ou informais, e são considerados imprescindíveis, haja vista a quantidade de informações a serem tratadas, para a formalização da inteligência competitiva (CHOO, 2003).

A gestão da informação tem como principal objetivo identificar e potencializar recursos informacionais e informação disponíveis, tornando a organização capaz de aprender e adaptar-se às mudanças que a envolvem por meio da aplicação do ciclo da informação. $\mathrm{O}$ 
ciclo inicia com a identificação de uma necessidade informacional, continua com a busca por uma solução para o problema identificado, passando pelo reconhecimento de quem gerou esta informação, assim como suas fontes e acesso, formas seleção, aquisição, registro, representação, recuperação, análise e disseminação da informação, que, uma vez utilizada, aumenta o conhecimento individual e coletivo (TARAPANOFF, 2006). A gestão de recursos informacionais é legítima diante da necessidade de integrá-los e coordená-los, frente à diversidade de recursos existentes na organização (FROEHLICH, 1989).

Seguindo este pensamento, Wilson (1997) define a gestão da informação como a aplicação dos princípios administrativos na aquisição, organização, controle, disseminação e uso da informação na organização, seja ela pública ou privada. Em outro conceito, Davenport (1994) define gestão da informação como a gestão de todo ambiente informacional de uma organização. No entanto, ao executar a gestão da informação em uma organização, exige-se atenção a vários aspectos, dentre eles: o domínio de diferentes formas de informação que circulam na organização; o conhecimento dos seus fluxos - formais e informais; ao ciclo de vida de cada informação circulante; e, finalmente, a disseminação de como utilizar a informação e sua cultura informacional (MORAES; FADEL, 2008).

Desse modo, torna-se relevante para a gestão da informação o valor, a qualidade, a posse, o uso e a segurança da informação, de forma a apoiar a estratégia global da organização, tornando mais eficientes o conhecimento, os recursos informacionais e as conexões exigentes entre os vários sistemas que a compõem (WILSON, 1997; BRAGA, 2000).

\subsection{GESTÃO DO CONHECIMENTO}

Com a disseminação do uso estratégico da informação incorporou-se ao valor da empresa aspectos "intangíveis", medidos de acordo com o valor da marca, patentes geradas, inovações, capital intelectual de seus colaboradores, em especial dos gestores do alto escalão, entre outros. Este aspecto tornou-se essencial nas organizações, pois, delas se esperam melhores práticas e soluções, ideias novas, processos de descoberta, novos insights, enfim, algo que a informação, por melhor gestão que tenha, não pode fornecer sozinha (LEV, 2004; DAVENPORT; PRUSAK, 1998)

Assim surgiu a definição de gestão do conhecimento, que trabalha a informação e o conhecimento, com o objetivo de aumentar a capacidade de adaptação da empresa ao meio 
que a envolve, com inovação e competência, ampliando sua eficácia e aprendizagem organizacional (TREHAN, 2005).

Autores como Spender (1996), Sveiby (1998), Nonaka e Takeuchi (1997), Tanaka (2000), Borghoff e Pareschi (1998) e Davenport e Prusak (1998) defendem a existência de dois tipos de conhecimento: o explícito e o tácito. O conhecimento explícito tem por característica ser facilmente replicado, de maneira sistematizada, dentro de uma organização. Normalmente, encontra-se expresso em documentos formais onde constam informações sobre a própria organização, tais como, organogramas, relatórios, estatutos, entre outros. Enquanto que o conhecimento tácito, considerado pela literatura, mais relevante que o primeiro, referese ao capital intelectual e a experiência individual dos que formam a organização. Envolvido em grande parte por uma dimensão cognitiva é mais difícil de ser articulado e transmitido de maneira formalizada

O conhecimento tácito na organização possui três componentes: o consciente - que ocorre quando o indivíduo pode explicar o que faz; o automático - que ocorre quando o indivíduo não sabe explicar o que faz; e o coletivo - tipo de conhecimento desenvolvido pelo indivíduo e partilhado com a equipe (SPENDER, 1996).

Porém, novos conhecimentos surgem a partir da conversão do conhecimento tácito em explícito, ou seja, de ideias individuais compartilhadas com outros indivíduos na organização, gerando valor para esta (MORESI, 2001).

Nonaka e Takeuchi (1997) sugerem que a conversão do conhecimento passa por quatro processos, resultantes de duas formas de interação:

- do conhecimento tácito para o explícito ou externalização, ou seja, a transformação de conhecimentos tácitos em explícitos realizado por meio de analogias, conceitos, hipóteses ou modelos;

- do conhecimento explícito para o próprio conhecimento explícito, envolvendo a combinação de diferentes conjuntos de conhecimento explícitos;

- do conhecimento explícito para o conhecimento tácito, ou internalização do conhecimento explícito no conhecimento tácito;

- do conhecimento tácito para o conhecimento tácito, ou socialização de experiências e, evoluindo, expressando o conhecimento tácito como modelos mentais ou habilidades técnicas compartilhadas. 
Reconhecendo a importância das estruturas cognitivas e afetivas comumente utilizadas pelos membros da organização em suas percepções, avaliações, explicações e senso de realidade, Choo, (1998) incluiu mais uma forma de conhecimento, o cultural. Este conhecimento utiliza suposições e crenças para expor a realidade, convenções e expectativas utilizadas para dar valor e significado às novas informações. Essa cultura torna-se o ponto de referência para a construção da realidade, reconhecimento de uma nova informação e avaliação e interpretação de alternativas (MORESI, 2001).

Em uma organização, o conhecimento cultural pode ser classificado em quatro tipos (SACKMANN, 1992):

- conhecimento de dicionário - inclui as descrições mais comuns, expressões e definições utilizadas na organização para descrever "o que" de situações;

- conhecimento de diretório - traz as práticas comuns e descrevem o "como" dos processos;

- conhecimento de manual - traz uma descrição minuciosa de como compor e aperfeiçoar estratégias para tomada de decisão;

- conhecimento axiomático - explicam as razões e explanações das causas finais ou das premissas a priori que são consideradas no "por que" os eventos acontecem.

Ao citar que "o recurso econômico básico não é mais o capital nem os recursos naturais ou a mão de obra e sim o conhecimento; uma sociedade na qual os trabalhadores do conhecimento desempenham um papel central”, Drucker (1993, p.33) afirma que o mundo entra na era da Sociedade do Conhecimento, cujo impacto social será amplo.

Neste contexto, Drucker (1993) destaca a importância do capital intelectual e o valor do conhecimento nesta nova sociedade, mudando o foco da gestão, antes centrada na máquina, para o foco na atuação do homem. Assim, no que se refere ao conhecimento, a gestão da informação está alinhada com o conhecimento explícito e a gestão do conhecimento com o conhecimento tácito, pois este preocupa-se com a capacidade das pessoas em transmitir e compartilhar seus conhecimentos. Quando transmitido, o conhecimento transforma-se em informação (TARAPANOFF, 2006).

Gestão do conhecimento pode ser definida como um conjunto de ações utilizadas na busca e no controle de toda forma de conhecimento existente em uma organização, com o intuito de utilizá-la na execução de seus objetivos. Estas ações devem ter como meta principal 
apoiar a tomada de decisão, em todos os níveis organizacionais, de forma a representar um motivo de mudança no comportamento organizacional (MORESI, 2001).

Segundo Rodrigues e Maccari (2003), a gestão do conhecimento corresponde a um conjunto de ferramentas que automatiza os relacionamentos entre informação, usuários e processos, considerado fator fundamental para todas as pessoas e organizações que desejam sobressaírem-se em um mundo cada vez mais competitivo.

A informação deve ser utilizada pelas organizações para gerar valor, construir conhecimento e tomar decisões, representando, dessa forma, inovação e vantagem competitiva. A gestão do conhecimento, por meio do conhecimento produzido no processo de inteligência competitiva, concebe poder à informação, que poderá ser reutilizada por outros membros da organização, em ocasiões diferentes, enriquecida e reciclada (TARAPANOFF, 2006; SEELEY; DAVENPORT, 2006).

Constituir parcerias para aprendizagem organizacional, transferindo conhecimentos compatíveis com a cultura e o estilo operacional da organização parceira, faz parte do que se chama conexão do conhecimento (BADARACCO, 1991). Nesse contexto, a organização que realizar com eficiência os processos de criação de significado, construção do conhecimento e tomada de decisão podem ser consideradas uma organização do conhecimento (TARAPANOFF, 2006).

\section{METODOLOGIA}

Esta pesquisa é classificada, quanto à abordagem, como qualitativa. Também pode ser classificada como exploratória, pois fundamentado em Queiróz (1992), esta tem por objetivo conhecer a variável de estudo tal como se apresenta, seu significado e o contexto onde ela inserida. Pressupõe-se que o comportamento humano é melhor compreendido no contexto social onde ocorre (QUEIRÓZ, 1992).

Em relação ao procedimento de condução da pesquisa, esta é classificada como um estudo de caso, que é definido por Yin (2015) como uma verificação empírica que investiga um fenômeno contemporâneo dentro de seu contexto da vida real. É uma forma de pesquisa que aborda com profundidade um ou poucos objetos de pesquisa, desta forma tem pequena amplitude, porém procura conhecer em profundidade a realidade de uma pessoa, de um grupo de pessoas, de uma ou mais organizações, uma política econômica, um programa de governo, 
um tipo de serviço público, entre outros, cuja característica principal é a profundidade do estudo (ZANELLA, 2009).

Para a elaboração deste artigo, além de pesquisa documental, realizou-se entrevistas conduzidas por meio de um roteiro semiestruturado com os Secretários e os Pró-reitores da Universidade Federal de Mato Grosso, no mês de janeiro de 2017.

A análise das respostas se divide em três etapas. A primeira etapa permite descobrir o entendimento dos entrevistados quanto ao conceito e função da Gestão do Conhecimento (GC). A segunda possibilita descobrir se há apoio da alta gestão à implantação da GC e se esta é considerada prioridade pela mesma. A terceira permite verificar quais os obstáculos à implantação de processos de GC na UFMT, no que tange ao apoio da alta administração e prioridades, aos Recursos Humanos, à Infraestrutura tecnológica, à comunicação interna e externa e ao processo de trabalho e cultura organizacional.

A seguir, discute-se cada uma das etapas, destaque-se que a análise e sistematização dos dados foram feitos sob a luz de referencial teórico sobre a temática.

\subsection{OBJETO DE ESTUDO}

A Universidade Federal de Mato Grosso, fundada em 10 de dezembro de 1970, é a única Universidade Federal no Estado, atende a região Centro Sul, com os cursos da sede, situada na capital, Cuiabá e encontra-se em ampliação com a construção do Câmpus II, onde funcionarão os cursos da área da saúde. Atualmente, além do campus sede, existem outros quatro no interior do estado, o Campus de Várzea Grande, em fase de implantação, localizado na região metropolitana, o Campus de Rondonópolis que abrange a região sul do estado; o Campus do Araguaia, com duas unidades, atendendo a região leste e o Campus de Sinop, na região norte do Estado, além de possuir 24 Polos de educação a distância.

A UFMT é composta por 32 institutos e faculdades, que ofertam graduação em 106 cursos presenciais e 6 a distância, além de 62 cursos de mestrado e doutorado. Em 2016, contava com uma população universitária superior a 25.000 pessoas entre docentes, técnicos e alunos. Por meio das turmas regulares, turmas especiais, Licenciaturas Parceladas, cursos de formação continuada e da educação a distância, atinge mais de 80, dos 141 municípios de Mato Grosso, alguns distantes mais de 800 km de Cuiabá (UFMT, 2017). 
A administração da UFMT é composta pela Reitoria, Vice-Reitoria, Órgãos Colegiados, 11 Pró-reitorias, 04 Secretarias, Coordenações, Diretorias dos Institutos/Faculdades e Gerências.

Faz parte de sua estrutura uma base de pesquisa no Pantanal, duas fazendas experimentais, dois hospitais veterinários e um hospital universitário, este último com atendimento integral pelo Sistema Único de Saúde/SUS (UFMT, 2017).

\section{RESULTADOS E DISCUSSÃO}

A gestão do conhecimento é um instrumento para a automação dos relacionamentos entre informação, usuários e processos, indispensável às organizações para competirem no mercado, ou seja, as organizações devem usar a informação para criar significado, construir, conectar e converter conhecimento. Nesta conversão do conhecimento, a organização busca transformar o conhecimento tácito de indivíduos criativos em conhecimento explícito e este conjunto de atividades deve ter como principal meta o apoio ao processo decisório em todos os níveis (NONAKA; TAKEUCHI, 1995; RODRIGUES; MACCARI, 2003; MORESI, 2001; TARAPANOFF, 2006).

Neste sentido, questionou-se aos Pró-reitores e Secretários, no seu entendimento, qual seria o significado da Gestão do Conhecimento. Foi observado unanimidade nas respostas positivas em relação à familiaridade com o termo Gestão do Conhecimento (GC), apesar de afirmarem não terem tido treinamento formal acerca do tema. Entretanto, os entrevistados evidenciaram componentes diversos da GC, como por exemplo: a administração do conhecimento com o intuito de potencializar os resultados, o compartilhamento dos saberes para transformação de conhecimento tácito em explícito e o gerenciamento da informações e conhecimento para delinear estratégias a ações de planejamento. Portanto, as respostas fornecidas podem ser entendidas como conceitos de GC que se complementam.

Ao serem questionados sobre a obtenção e sistematização das informações externas e sua divulgação e utilização na IES, somente 14,28\% dos respondentes afirmam existir, não como ação institucional, mas como ação específica de grupos de pesquisa, segundo seus interesses.

No tocante à existência de uma pessoa ou um grupo dedicado a investigar os novos recursos da Tecnologia de Informação, observou-se pelas respostas que apenas 28,57\% responderam que há essa iniciativa, entretanto, não há uma pessoa ou um grupo de pessoas na 
universidade especialmente dedicado a coletar e analisar informações internas, alinhando-as às externas e nem relativas às melhores práticas de Gestão do Conhecimento na IES, ou seja, em relação à existência da Inteligência Competitiva (IC) na UFMT, percebeu-se que esta é incipiente, pois quando ocorrem, são de forma isolada e informal, confrontando Battaglia (1998) quando afirma que a IC é decorrência de um processo formal que acompanha, tanto os ambientes internos quanto externos e as informações obtidas, sejam formais ou informais, são coletadas, processadas e disseminadas, tanto nos níveis estratégicos quanto táticos, com o objetivo de definir, executar e efetivar as estratégias da organização.

Ao serem questionados sobre de quem foi a iniciativa de introduzir a gestão do conhecimento na Instituição, $85,57 \%$ desconhecem essa informação e os que têm esse conhecimento afirmam que foi a Reitora e que os mecanismos utilizados para a definição da política ou estratégia de gestão do conhecimento da Instituição foram compromissos assumidos pela equipe de recursos humanos, de TI e redes de conhecimento. Para estes respondentes, a GC na UFMT está em fase de implantação, como exemplo foram citadas iniciativas de GC em suas áreas de atuação, o mapeamento e sistematização da produção científica gerada pela UFMT e o sistema de informatização específico para os cursos de pósgraduação stricto sensu - SIPG.

No que tange à percepção da importância de GC na instituição, verificou-se que não há um consenso nas respostas, pois para uns, a gestão do conhecimento faz parte das prioridades estratégicas da instituição e para outros, a gestão do conhecimento não é uma prioridade estratégica, mas certamente será nos próximos dois anos. Em outro questionamento, verificou-se que a percepção da $\mathrm{GC}$ em relação aos níveis da estrutura organizacional é considerada mais elevada pela alta administração, média pela gerência e baixa pelos demais servidores, fato comprovado com a resposta do próximo item que trata da existência de uma estratégia explícita de gestão do conhecimento, em que 85,71\% afirmaram não estar amplamente disseminada na Instituição e que a mesma não é bem conhecida pela maioria.

Ao serem questionados sobre o grau de formalização da GC na instituição percebeu-se que os Pró-reitores têm uma visão diferenciada dos Secretários. Os Pró-reitores concordam que existe um grupo formal de trabalho que discute os conceitos, as práticas e as ferramentas de GC e que, apesar de ainda não serem suficientes os recursos (humanos, financeiros e infraestrutura) para GC, estes são crescentes e mostram um efetivo compromisso da 
Instituição. No entanto, divergem entre si no que se refere a existência de mandato e objetivos de GC bem definidos na organização.

Para os secretários, a GC trata-se de um conceito abstrato discutido por pequenos grupos informais cuja importância dada aos objetivos de GC por meio de discursos e política, ainda não se refletiu na alocação de recursos, o que pode se verificar com a transcrição de uma das entrevistas:

Desconheço a existência de uma estratégia institucional para esta finalidade. Conheço muitas ações que poderiam estar enquadradas no escopo de ações de GC, como por exemplo a capacitação de servidores, o estímulo à documentação, mas desconheço a existência de um projeto de Gestão de Conhecimento (Sec. 3).

Talvez essa visão seja consequência de uma maior atuação dos Pró-reitores nos conselhos universitários por força regimental, o que corrobora com a resposta dada de que não há uma estratégia explícita e amplamente disseminada de gestão do conhecimento na Instituição e que, por este motivo, não é bem conhecida pela maioria dos servidores.

Para os entrevistados que afirmam existir iniciativas para a GC, os elementos-chave de uma política ou uma estratégia de GC na UFMT incluem: gestão da informação, aspectos de tecnologia da informação, aspectos de gestão de recursos humanos e aspectos organizacionais. Entretanto há algumas divergências de entendimento ao designarem a intensidade de uso desses elementos facilitadores no processo de implantação de GC, dentre elas podem-se apontar: os programas de capacitação para o pessoal, considerados de baixo uso para uns e médio para outros; para os respondentes, de maneira geral, existe alta prioridade dada à iniciativa de GC no nível mais alto da hierarquia; a troca de experiências com outras organizações que estão envolvidas no processo de GC, foi considerada média e baixa, no entanto os sistemas de informática que apoiam os processos de GC foram classificadas como médio e alto.

Quanto aos principais obstáculos à implantação de processos de GC na UFMT foi identificado que há falta de comprometimento dos diretores no item relacionado ao apoio da alta administração na implantação de GC, apontado como o principal obstáculo pela maioria dos respondentes, classificada como alta. Os respondentes também classificaram como um obstáculo médio e baixo para a implantação da $\mathrm{GC}$, a prioridade do governo. Em relação ao "Receio de que outros órgãos/público em geral poderiam ter acesso a informações sigilosas/confidenciais", não foi apontado como um obstáculo, pois foi considerado baixo por 
todos os respondentes. A maioria dos respondentes classificou como obstáculo médio à implantação de GC "estratégias de gestão do conhecimento são adaptadas ao setor privado, mas são inadequadas ao setor público", entretanto, para 14,28\% dos respondentes, são perfeitamente aplicáveis em uma gestão pública, especialmente nas universidades, o que vai ao encontro da opinião de Wilson (1997) que define a gestão da informação como a aplicação dos princípios administrativos na aquisição, organização, controle, disseminação e uso da informação na organização, seja ela pública ou privada.

Em relação aos obstáculos à implementação da GC relacionados aos Recursos humanos dedicados à implantação, verificou-se que há alta deficiência na capacitação de pessoal, baixa compreensão sobre gestão do conhecimento na Instituição, bem como uma tendência da gestão em concentrar esforços na tecnologia de informação e de comunicação, em vez de em questões organizacionais ou ligadas às pessoas, este fato chama a atenção, pois conforme de Davenport e Prusak (1998), a tecnologia de informação deve ser vista como um elemento coadjuvante no sistema de inteligência competitiva, tendo como função impulsionar e facilitar a busca pela informação na organização, destacando ainda, que o sistema de inteligência competitiva deve estar orientado para pessoas, com necessidades e culturas específicas.

Nesta linha, no que tange à infraestrutura tecnológica, foi identificado não ser um obstáculo à implementação da GC as deficiências na infraestrutura computacional, redes, servidores, etc, mas que a pouca propensão para investimento em tecnologias voltadas essencialmente para facilitação do aprendizado e colaboração influencia em sua implementação. Destaca-se que Rodrigues e Toledo (2011), defendem que a inteligência competitiva contribui com a estratégia da empresa, principalmente, com o processamento adequado da informação, levando a capacitação de pessoas e sistemas.

No tocante à visibilidade e comunicação interna e externa, a falha de comunicação foi considerada um obstáculo médio à implantação da GC, mas que apesar disso, a instituição tem obtido algum sucesso na implantação de GC.

Dentre os obstáculos apontados pelos entrevistados, o de maior destaque à implantação da GC encontra-se relacionado ao processo de trabalho/cultura organizacional, pois foi identificado que existe alta resistência de certos grupos de servidores/cultura organizacional a mudanças, além disso os entrevistados responderam que há falta de tempo ou de recursos para compartilhar conhecimento concretamente na rotina diária, bem como a 
dificuldade em capturar o conhecimento não-documentado, o que pode ser explicado pela falta de incentivos para o compartilhamento de conhecimento, classificado como um obstáculo médio.

\section{CONCLUSÃO}

Neste trabalho procurou-se identificar as práticas de Gestão de Informação e do Conhecimento utilizadas pela gestão da Universidade Federal de Mato Grosso. Para tanto, realizou-se um estudo de caso, por meio de entrevistas com roteiro semiestruturado com os Pró-reitores e Secretários da Universidade Federal de Mato Grosso, bem como análise documental.

Como resultado do estudo observou-se que, apesar de não terem tido um treinamento formal sobre GC, todos têm familiaridade com o seu significado e sua relevância e reconhecem que há iniciativas de GC na instituição. Entretanto, salientam, que não há uma pessoa, ou um grupo de pessoas na Universidade especialmente dedicado a coletar, analisar informações internas e alinhá-las às externas, assim, em relação à existência da Inteligência Competitiva (IC) na UFMT percebeu-se que esta é incipiente, pois quando ocorre, é de forma isolada e mostra que a GC na instituição encontra-se em fase de implantação.

Verificou-se também que não há uma estratégia explícita de gestão do conhecimento e, por isso, esta não é amplamente disseminada na Instituição. Percebeu-se que, tanto a gestão da informação quanto a do conhecimento na UFMT são mais difundidas e disseminadas entre os Pró-reitores que entre os Secretários, talvez pelo fato destes serem mais atuantes nos conselhos universitários por força regimental.

Foram identificados como principais obstáculos, na visão dos entrevistados, à implantação da GC: falta de comprometimento dos diretores no item relacionado ao apoio da alta administração na implantação de GC; deficiência na capacitação de pessoal; baixa compreensão sobre GC na Instituição; tendência da gestão em concentrar esforços apenas na tecnologia de informação e de comunicação e desconsiderar as questões organizacionais ou ligadas às pessoas; falta de tempo ou de recursos para compartilhar conhecimento e dificuldade em capturar o conhecimento não-documentado. Como maior obstáculo à implantação da GC na UFMT identificou-se o processo de trabalho e cultura organizacional, pois existe uma alta resistência de certos grupos de servidores a mudanças. 
Com a posse da nova gestão, em outubro de 2016, espera-se que esses obstáculos sejam superados, pois observa-se uma nova visão no processo de Gestão do Conhecimento e da Informação.

A gestão do período 2012 a 2016, impulsionada pela conjuntura econômica e pela política do governo federal favorável às universidades públicas, foi pautada na expansão e interiorização do ensino, tanto de graduação quanto de Pós-Graduação.

Na nova gestão, por haver uma política clara de contenção de gastos por parte do governo federal, o mote deve ser a consolidação do que foi feito pela gestão anterior, ou seja, através dos dados disponíveis na instituição, realizar estudos estratégicos com o objetivo de melhorar os indicadores institucionais, possibilitando à Instituição, de forma criativa e inovadora, verificar quais alternativas podem ser desenvolvidas para que se tenha maximização da utilização dos recursos disponíveis.

No que tange aos recursos humanos, uma ação já foi iniciada pela Coordenação de Desenvolvimento Humano/CDH por meio do levantamento das competências dos servidores, dando destaque a quais pontos deveriam ser melhorados para o bom desempenho de suas atividades.

Outra ação institucional, foi a criação do Escritório de Projetos e Processos - EPP, revelando uma preocupação com o desenvolvimento de práticas ligadas à gestão da informação e do conhecimento, à medida que a atribuição do EPP é fazer o mapeamento dos processos das unidades, de forma que se possa planejar e melhor alocar recursos, principalmente humanos, evitando desta forma, retrabalho. Outra característica deste escritório é a de fazer com que as unidades aproveitem melhor os seus dados e as informações produzidas internamente, para que haja uma interação/integração com outras unidades a fim de que se possa efetivamente auxiliar a gestão na tomada de decisão.

Na gestão atual, a Pró-reitoria de Planejamento - PROPLAN passou a assumir sua função principal, ou seja, ser responsável pelo planejamento institucional. Observa-se que com este foco, a partir dos dados que obrigatoriamente têm que ser fornecidos, seja aos órgãos de controle seja para a regulação junto ao Ministério da Educação, sejam desenvolvidos estudos que os qualifiquem, para que a gestão consiga fazer seu planejamento estratégico, estabelecendo critérios bem definidos para melhor gestão de seu orçamento, traçando objetivos e ações para elevar seus indicadores, sejam de qualidade ou de desempenho. 
Portanto, para que se obtenha sucesso de fato na implantação de GC é necessário que haja mudança de mentalidade, que se abandone a desarticulação dos setores rumo à implantação de novos processos de trabalho, priorizando o compartilhamento de conhecimento de forma articulada, e para que haja algum progresso neste sentido, é necessário que se trabalhe a qualificação dos recursos humanos, disseminando, posteriormente, práticas de mapeamento, classificação, sistematização e difusão do conhecimento.

Classificamos como um fator limitante da pesquisa a opção por entrevistar apenas os Pró-reitores e os Secretários da alta gestão da UFMT. No entanto, esta opção se deu pelo fato das informações ficarem restritas às duas categorias, cuja relevância está no conhecimento amplo que os mesmos têm da Instituição e, principalmente, da gestão.

Como proposta de trabalho futuro, sugere-se ampliar as entrevistas com outros setores administrativos da UFMT, envolvendo as coordenações, as gerências e as diretorias dos institutos/faculdades, com o objetivo de verificar se as respostas obtidas nessa pesquisa mudariam com os novos resultados encontrados.

\section{REFERÊNCIAS}

BADARACCO, J. et al. The knowledge link: How firms compete through strategic alliances. Harvard Business Press, 1991.

BATTAGLIA, M. G. B. L. Intelligence compétitive comme support pour la construction d'un modèle de Système d'Information des Clients pour la FINEP. Rio de Janeiro/Marseille, CEIC/DEA. Mémoire en vue de l'obtention du Diplome d'Etudes Approfondies-DEA, 1998.

BORGHOFF, U.; PARESCHI, R. Information technology for knowledge management. Berlin: Springer-Verlag, 1998.

BRAGA, A. A gestão da informação. Millenium, 2000

BRASIL. Ministério da Educação. Instituto Nacional de Estudos e Pesquisas Educacionais Anísio Teixeira (Inep). Sinopses Estatísticas da Educação Superior 2017. Brasília: Inep, 2018. Disponível em: <http://inep.gov.br/sinopses-estatisticas-da-educacao-superior >. Acesso em: 17 mar. 2019.

$\mathrm{CHOO}, \mathrm{C} . \mathrm{W}$. Information Management for the intelligent Organization: The art of scanning the environment, 3rd. Medford, NJ: Information Today. 1998. 
A organização do conhecimento: como as organizações usam a informação para criar significado, construir conhecimento e tomar decisões. São Paulo: Senac São Paulo, 2003.

CORREIA, C. C. Getting Competitive: Competitive Intelligence is a Smart next Step for Information Pros. Library journal, v. 131, n. 7, p. 52, 2006.

DAVENPORT, T. H. Reengenharia de processo: como inovar na empresa através da tecnologia da informação. Rio de Janeiro: Campus, 1994.

DAVENPORT, T. H.; PRUSAK, L. Conhecimento empresarial: como as organizações gerenciam o seu capital intelectual. Rio de Janeiro: Campus, 1998.

DAVIS, I; STEPHENSON, E. Ten trends to watch in 2006. The McKinsey Quarterly, v. 1, p. 1-5, 2006.

DAY, G. S. Manutenção da vantagem competitiva: criação e sustentação das vantagens em ambientes competitivos dinâmicos. DAY, G. S.; REIBSTEIN, D. J. A dinâmica da estratégia competitiva. Rio de Janeiro: Campus, p. 59-85, 1999.

DISHMAN, P. L.; CALOF, J. L. Competitive intelligence: a multiphasic precedent to marketing strategy. European Journal of Marketing, v. 42, n. 7/8, p. 766-785, 2008. DRUCKER, P. F. Produtividade - A chave do futuro. Diálogo, v. 26, n. 4, p. 33, 1993.

FIALHO, A. S. Análise do uso da Inteligência Competitiva no setor da construção de imóveis residenciais na cidade de Porto Alegre. 180f. Dissertação (Mestrado em Administração e Negócios)-Pontifícia Universidade Católica do Rio Grande do Sul, Porto Alegre, 2010.

FROEHLICH, T. J. The foundations of information science in social epistemology. In: [1989] Proceedings of the Twenty-Second Annual Hawaii International Conference on System Sciences. Volume IV: Emerging Technologies and Applications Track. IEEE, p. 306-314. 1989.

FULD, L. M. Inteligência competitiva: como se manter à frente dos movimentos da concorrência e do mercado. Elsevier, 2007.

GOMES, E.; BRAGA, F. Inteligência competitiva: como transformar informação em um negócio lucrativo. Campus, 2001.

HERRING, J, P. Key intelligence topics: a process to identify and define intelligence needs. Competitive Intelligence Review: Published in Cooperation with the Society of Competitive Intelligence Professionals, v. 10, n. 2, p. 4-14, 1999.

HERRING, J. P. Create an Intelligence Program: for Current and Future Business Needs. Competitive Intelligence Magazine, v. 8, n. 5, p. 20-27, 2005. 
KAHANER, L. Competitive intelligence: how to gather analyze and use information to move your business to the top. Simon and Schuster, 1997.

LEV, B. Sharpening the intangibles edge. Harvard Business Review, v. 6, p. 109-116, 2004.

MENEZES, E. M. Inteligência competitiva: uma revisão de literatura. RDBCI: Revista Digital de Biblioteconomia e Ciência da Informação, v. 3, n. 2, p. 103-130, 2005.

MILLER, J. Qualificações e treinamento para a inteligência. O milênio da inteligência competitiva. Porto Alegre: Bookman, cap, 4, p. 79-92, 2002.

MORAES, CRB; FADEL, B. Triangulação metodológica para o estudo da gestão da informação e do conhecimento em organizações. Gestão da informação e do conhecimento. São Paulo: Polis, p. 27-40, 2008.

MORESI, E. A. D. Inteligência organizacional: um referencial integrado. Ciência da informação, v. 30, n. 2, 2001.

NONAKA, I.; TAKEUCHI, H. The knowledge-creating company: How Japanese companies create the dynamics of innovation. Oxford university press, 1995.

NONAKA, Ikujiro; TAKEUCHI, Hirotaka. Criação de conhecimento na empresa: como as empresas japonesas geram a dinâmica da inovação. 9. ed. Rio de Janeiro: Campus, 1997.

PEREIRA, F. A. B. et al. A Gestão de Conhecimento na Modernização da Gestão Universitária: o caso da UERN (RN), 2011.

QUEIROZ, M. I. P. O pesquisador, o problema da pesquisa, a escolha de técnicas: algumas reflexões. LANG, ABSG, org. Reflexões sobre a pesquisa sociológica. São Paulo, Centro de Estudos Rurais e Urbanos, p. 13-29, 1992.

RODRIGUES, L. C.; MACCARI, E. A. Gestão do conhecimento em instituições de ensino superior. Revista de Negócios, v. 8, n. 2, 2003.

RODRIGUES, L. C.; RICCARDI, R. Inteligência competitiva: nos negócios e organizações. Maringá: Unicorpore, 2007.

RODRIGUES, L. C.; SIERRA, J. C. V.; RECHZIEGEL, W. Maturidade Organizacional em Inteligência Competitiva - O Caso de uma Instituição Financeira Brasileira. Revista de Ciências da Administração, v. 16, n. 38, p. 126-139, 2014.

RODRIGUES, L. C.; TOLEDO, L. A. Alinhamento entre sistema de inteligência competitiva e gerenciamento da tecnologia de informação. Revista Inteligência Competitiva, v. 1, n. 1, p. 40-62, 2011.

SACKMANN, S. A. Culture and subcultures: An analysis of organizational knowledge. Administrative science quarterly, v. 37, n. 1, p. 140-161, 1992. 
SEELEY, C. P.; DAVENPORT, T. H. KM MEETS BUSINESS INTELLIGENCE

Knowledge and data have long been maintained as separate entities, but is it now time to formally integrate the two? Knowledge Management Review, v. 8, n. 6, p. 10, 2006.

SILVA, P. N.; MUYLDER, C. F. Inteligência competitiva e cooperação na percepção dos atores do arranjo produtivo local de software da Região Metropolitana de Belo Horizonte. Perspectivas em Ciência da Informação, v. 20, n. 2, p. 134-157, 2015.

SIQUEIRA, M. C. Gestão estratégica da informação. Brasport, 2005.

SPENDER, J. C. Organizational knowledge, learning and memory: three concepts in search of a theory. Journal of organizational change management, v. 9, n. 1, p. 63-78, 1996.

STAREC, C. et al. Gestão da informação, inovação e inteligência competitiva: como transformar a informação em vantagem competitiva nas organizações. São Paulo: Saraiva, 2012.

SVEIBY, K. E. A nova riqueza das organizações. Rio de Janeiro: Campus, 1998.

TANAKA, I. Gestão do Conhecimento. Rio de Janeiro: Campus, 2000.

TARAPANOFF, K. Referencial teórico: introdução. In: Inteligência organizacional e competitiva. Brasília: UnB, p. 33-49, 2001.

TARAPANOFF, K. Inteligência, informação e conhecimento em corporações. Instituto Brasileiro de Informação em Ciência e Tecnologia (IBICT), 2006.

TREHAN, R. Core or competitive competence in hospitality industry. National Hotel Exchange and CBK Family, v. 3, p. 89, 2005.

UFMT, Universidade Federal de Mato Grosso. Portal da Universidade Federal de Mato Grosso - UFMT. <Disponível em: http://www.ufmt.br/ufmt/site/>. Acesso em: 12 fev. 2017.

VALENTIM, M. L. P. et al. O processo de inteligência competitiva em organizações. DataGramaZero, Rio de Janeiro, v. 4, n. 3, p. 1-23, 2003.

WILSON, T. D. Information Management. In: International Encyclopedia of Information and Library Science, (Routledge), 187-196, 1997.

YIN, Robert K. Estudo de Caso: Planejamento e Métodos. Bookman editora, 2015.

ZANELLA, Liane Carly Hermes. Metodologia de estudo e de pesquisa em administração. Florianópolis: Departamento de Ciências da Administração/UFSC, 2009. 